\section{Patient choice in psychiatry}

\author{
CHIARA SAMELE, SIMON LAWTON-SMITH, \\ LESLEY WARNER and JEEVI MARIATHASAN
}

\begin{abstract}
Summary The government has embarked on an ambitious plan to make patient choice central to the way healthcare and treatment are delivered. Mental healthcare is incorporated into this agenda. This editorial considers the implications of patient choice for psychiatry and some of the main challenges associated with this policy.
\end{abstract}

Declaration of interest None.

Choice of care is viewed as important to the modernisation of health and social care services, and has formed part of the government's new delivery plan outlined in Creating a Patient Led NHS (Department of Health, 2005). Increasing choice is expected to create better alignment between what patients want and what services subsequently provide. It aims to promote greater patient autonomy, involvement and empowerment in the treatment and care received, to expand the range of available services, to help reduce waiting lists and to improve the quality of care through competition.

\section{IMPLICATIONS OF CHOICE}

The implications of patient choice are potentially huge for both patients and health and social care managers and staff. Choice places treatment or care decisions squarely with the patient. This is different to shared decision-making which involves at least two people (a clinician and a patient) agreeing which treatment option to implement (Charles et al, 1997). Informed choice is difficult to define and keep distinct from shared decision-making, participation or collaborative approaches. One definition includes 'obtaining useful information from the practitioner or professional and then deciding individually or collaboratively on the best course of action that promotes independence, recovery and an improved quality of life' (New York State Office of Mental Health, 2004). The provision of information alone, however, is not sufficient. It must be understood and presented in a balanced way so as not to suggest a right or wrong choice (Hope, 2002).

Critics of choice highlight concerns about the practical implementation and the potentially negative consequences to the patient. At an organisational level, creating the type of infrastructure required to support patient choice is complex. An effective health service based on choice requires fundamental changes to managerial and information systems, more time for consultations and a highly coordinated system to guide patients to appropriate care settings once choices have been made (Goodwin, 2006). At an individual level, Schwartz (2004) contends that too much choice can be debilitating, requiring more time to make decisions, with an increased risk of mistakes in decision-making and more negative psychological consequences to the patient.

\section{CHOICE AND PSYCHIATRY}

A framework has been developed which sets out the government's vision for choice in mental health. This includes four 'choice points': promoting and supporting life choices (e.g. work, education, leisure, housing, self-help, direct payments); access and engagement (choice of how to contact mental health services, including in an emergency, and the role of advance directives); assessment (choice of when and where assessments take place); and informed choice of service or treatment and care pathway (including patients being supported to make their own decisions) (Care Services Improvement Partnership, 2006).
It might be particularly challenging for psychiatry to take on board this agenda for patient choice. To date acute physical healthcare and elective surgery are the main areas for patient choice. Initiatives such as 'choose and book' enable patients to select up to five different service providers and book appointments at preferred times. However, these initiatives might not be the best models for modern mental health services, whose ethos includes breaking down stigma and creating social inclusion by providing opportunities for employment and social activities (Valsraj \& Gardener, 2007). The recovery model for mental health underpins the choice agenda, in which a meaningful life can be lived despite a diagnosis of serious mental illness (Lester and Gask, 2006). Recovery seeks to work outside the medical model, and move away from a paternalistic approach to decisionmaking, to allow patients to regain independence and to access services that they feel best meet their needs.

A fundamental issue concerning patient choice within psychiatry is the dilemma posed by caring for patients and at the same time protecting them and society from harm. Of importance to psychiatrists is the patient's capacity and competency to make valid treatment decisions. Using the example of anorexia nervosa, Henderson (2005) highlights how the capacity for choice and self regulation of behaviour becomes a core part of treatment. He goes on to suggest that individuals are helped to regain their own volitional control, perhaps through cognitive psychotherapy. The danger, however, is that psychiatrists too readily assume that patients are not able to deal with information and choice. Hope (2002) suggests two methods to facilitate patient choice during a consultation: including patients' values in the decision analysis and giving patients the necessary high-quality information to allow them to make informed decisions.

However, choices for those with mental illness can quickly become limited for those at high risk of harming themselves or others. For example, the application of the government's proposed new powers of compulsory treatment, as set out in its Mental Health Bill 2006, will not take into account a patient's capacity to make decisions about their medical treatment. It is unclear how compulsory community treatment in particular would coexist alongside patient choice, whether choice would act to reduce these powers or vice versa. 


\section{INTERNATIONAL LESSONS}

What can we learn from how the choice agenda has been tackled elsewhere? Health departments from other high-income countries such as Australia, New Zealand, the USA and Canada broadly agree that patients should have more and better informed choice (Warner et al, 2006). In the USA it is accepted that consumer needs and choice should drive mental health services, but true choice is limited by the range of available services, and the complexity and lack of coordination between different agencies (statutory, voluntary and private). In a list of ten 'rules for quality mental health services in New York State', rule number one states 'There must be informed choice' (New York Office of Mental Health, 2004). Underpinning this document is a recovery-based principle in which informed choice includes obtaining useful information from the practitioner and an educational approach to medications and sideeffects. However, a key problem identified is the limited willingness of many psychiatrists to collaborate about decisions concerning medication, citing their professional training or lack of capacity of the individual to make their own decisions as reasons.

In Australia, New Zealand and Canada a range of mental health plans, strategies and guidance refers to the importance of choice, sometimes using the language of consumer participation (Warner et al, 2006). Key elements include adequate information for people to make informed choices, a range of alternative service providers and a recovery-based focus. However in practice choice is commonly not available. This might arise from health

CHIARA SAMELE, PhD, Sainsbury Centre for Mental Health, London; SIMON LAWTON-SMITH, BA, King's Fund, London; LESLEY WARNER, RMN, RGN, JEEVI MARIATHASAN, PhD, Sainsbury Centre for Mental Health, London, UK

Correspondence: Dr Chiara Samele, Sainsbury Centre for Mental Health, 134- 138 Borough High Street, London SEI ILB,UK. Email: chiara.samele@schmh.org.uk

(First received 28 September 2006, final revision 30 January 2007, accepted 7 February 2007)

professionals' reluctance to offer choices or through limitations on available services, primarily as a result of financial constraints both on services and on patients.

\section{FUTURE DIRECTION}

It is yet to be demonstrated whether patient choice will be fully embraced by psychiatry. The shift towards psychiatrists effectively handing over the reins to patients is likely to be gradual given the need to take account of issues such as capacity and risk. In addition, a better alignment between what patients want and what services they receive is dependent on factors, such as funding and service availability, which may be beyond psychiatrists' control.

The profession would, however, leave itself open to fair criticism if it fails to engage with the government's choice agenda. That agenda underpins much of the current reform in the National Health Service, and mental health patients should not be denied the possibility of the benefits that come from increased choice.

\section{REFERENCES}

Care Services Improvement Partnership (2006) Our Choices in Mental Health. http: / / www.csip-plus. org.uk/CPT/Our\%20Choicies\%20Doc\%20-\%20Final.pdf
Charles, C., Gafni, A. \& Whelan, T. (1997) Shared decision-making in the medical encounter: what does it mean? (or it takes at least two to tango). Social Science and Medicine, 44, 681-692.

Department of Health (2005) Creating a Patient Led NHS: Delivering the NHS Improvement Plan. Department of Health.

Goodwin, N. (2006) Patient choice: as attractive as it seems? A managerial and organizational perspective. Journal of Health Services Research and Policy, II, 129-130.

Henderson, S. (2005) The neglect of volition. British Journal of Psychiatry, 186, 273-274.

Hope, T. (2002) Evidence-based patient choice and psychiatry. Evidence-Based Mental Health, 5, 100-10।.

Lester, H. \& Gask, L. (2006) Delivering medical care for patients with serious mental illness or promoting a collaborative model of recovery? British journal of Psychiatry, 188, 401-402.

New York State Office of Mental Health (2004) 2005-2009 Statewide Comprehensive Plan for Mental Health Services. Appendix 4: Infusing Recovery-Based Principles into Mental Health Services. New York State Office of Mental Health. http: //www.omh.state.ny.us/ omhweb/statewideplan/2005/appendix4.htm

Schwartz, B. (2004) The Paradox of Choice: Why More is Less. Harper Collins.

Valsraj, K. M. \& Gardner, N. (2007) Choice in menta health: myths and possibilities. Advances in Psychiatric Treatment, 13, 60-67.

Warner, L., Mariathasan, J., Lawton-Smith, S., et a (2006) A Review of the Literature and Consultation on Choice and Decision-Making for Users and Carers of Mental Health and Social Care Services. Sainsbury Centre for Mental Health \& King's Fund. http: / /www.scmh org.uk/80256FBD004F6342/vWeb/pcKHAL6UED63 